\title{
STUDY ON INFORMATION MANAGEMENT FOR THE CONSERVATION OF TRADITIONAL CHINESE ARCHITECTURAL HERITAGE-3D MODELLING AND METADATA REPRESENTATION
}

\author{
Ya.Ning,Yen ${ }^{a}$ Kuo.Hua,Weng ${ }^{\text {b }}$ Hui.Yu, Huang ${ }^{c}$ \\ ${ }^{\text {a } A s s o c i a t e ~ P r o f e s s o r ~, C h i n a ~ U n i v e r s i t y ~ o f ~ T e c h n o l o g y, ~ C u l t u r a l ~ P r o p e r t i e s ~ R e s e a r c h ~ C e n t e r, ~ T a i w a n ~ T a i p e i ~, ~(~ a l e x @ c u t e . e d u . t w ~) ~}$ \\ b Researcher Assistant, China University of Technology, Cultural Properties Research Center, Taiwan Taipei \\ ${ }^{c}$ Associate Professor ,China University of Technology, Cultural Properties Research Center, Taiwan Taipei , ( ghwong@cute.edu.tw )
}

KEY WORDS: Traditional Chinese Architecture, BIM, SketchUP, Conservation

\begin{abstract}
:
After over 30 years of practise and development, Taiwan's architectural conservation field is moving rapidly into digitalization and its applications. Compared to modern buildings, traditional Chinese architecture has considerably more complex elements and forms. To document and digitize these unique heritages in their conservation lifecycle is a new and important issue. This article takes the caisson ceiling of the Taipei Confucius Temple, octagonal with 333 elements in 8 types, as a case study for digitization practise. The application of metadata representation and 3D modelling are the two key issues to discuss. Both Revit and SketchUp were appliedin this research to compare its effectiveness to metadata representation. Due to limitation of the Revit database, the final 3D models wasbuilt with SketchUp. The research found that, firstly, cultural heritage databasesmustconvey that while many elements are similar in appearance, they are unique in value;although 3D simulations help the general understanding of architectural heritage, software such as Revit and SketchUp, at this stage, could onlybe used tomodel basic visual representations, and is ineffective indocumenting additional critical data ofindividually unique elements. Secondly, when establishing conservation lifecycle information for application in management systems, a full and detailed presentation of the metadata must also be implemented; the existing applications of BIM in managing conservation lifecycles are still insufficient. Results of the research recommends SketchUp as a tool for present modelling needs, and BIM for sharing data between users, but the implementation of metadata representation is of the utmost importance.
\end{abstract}

\section{INTRODUCTION}

Nowadays, the application of digital techniques is one of the most prevalent discussions in the field of heritage conservation. Many modern technologies have been transferred into this field; such as LIDAR, UAV, GISand many other tools. BIM (Building Information Modelling System) is a newly developed digital technique to aid the management and $4 \mathrm{D}$ simulation of modern construction. Some researchers have also started to investigate the integration of BIM into cultural heritage preservation projects. In theory, BIM could provide a holistic platform to carryvarious levels of information,includingbuildings lifecycles, such asits background, planning, design and management. Together with complete 3D models, supported by the internal database, BIM seems to provide a solution to meetthe management needs of cultural heritage conservation. However, for digitizing traditional Chinese architecture, with its intricate details,generic elementsof BIMfails to meet the requirements - for modelling complex forms, or presenting all relevant heritage information. SketchUpis still the recommended method for 3D modelling, to be accompanied by charted metadata representation. This research focuses on how these two tools, SketchUp and metadata, can be efficiently applied to the conservation of traditional Chinese architecture. There are 2 main objectives:

a. To discuss a proper method for building 3D models of the elements.

b. To discuss the documenting process of recording traditional Chinese architectural elements for conservation, where establishing the metadata is the key.

With the digitization of the caisson ceiling in the Taipei Confucius temple as the case study, both Revit and SketchUpwere used for comparison in making 3D models, the metadata is then collected through documentation and research.

\section{THESIS REVIEW}

Using BIM to manage lifecycle information of cultural heritage is an emerging trend in the conservation field.Compared to BIM technology, many articles have already discussed howSketchUp wasapplied to digitize traditional Chinese architecture. This research reviewedtheses presented by both Western and Chinese researchers.

Among Western researchers, many articles pointed out BIM as a tool to help conservation in different aspects, such as development of the CityGML Geo BIM project-in integrating BIM and GIS(Leon, 2011). Fai utilized BIM by incorporating both quantitative and qualitative assets to provide a navigable timeline that chronicles tangible and intangible changes in the past and projections into the future(Fai, 2011). Murphy presented an HBIM(Historic Building Information Modelling) concept which is a prototype library of parametric objects based on historic data and a system of cross-platform programs for mapping parametric objects onto a point cloud and image survey data. The final HBIM product is the creation of full 3D models, including details behind the object's surface, concerning its methods of construction and materiality (Murphy, 2011). Murphy took a further step in 2012, integrating HBIM and 3D GIS (CityGML), for recording and managing cultural heritage Sites. He aimed to bridge the gap between parametric CAD modelling and 3D GIS while using benefits from both systems to help document and analyse heritage sites (Dore, 2012). BIM specializes in managing information for both individual elements, and establishing integrative platforms for information exchange. Regrettably, most of the researches mentioned above focus on the latter and visual simulation. They lack in discussing the representation of unique information for individual elements, which is hugely important to Chinese architectural heritage. 
Among Chinese researchers, Tan built a series of 3D models for the traditional Chinese architectural elements of the Qing Dynasty using ArchiCAD (Tan, 2006). The focus of this paper isstill on the establishment of a basic database. As for the information exchange of traditional building database, an open BIM concept was discussed to solve this problem(parametric relations for exchange in ArchiCAD, Digital Project and Revit). However, the main purposes of these studies were to establish a database of traditional Chinese architectural elements, as one of the special building types, for modern usage. The importance oflifecycle information ofcultural Heritage conservation was not mentioned in those studies. Some researchers tried to declare that the acquisition, organization, analysis and normalization of data are the key issues for developing cultural heritage BIM, but there are three more key aspects of cultural heritage BIM: the customized development on specialization functions in the BIM software, information interchange among different software, the interoperability management of GIS and BIM (Di, 2010). A clear concept was introduced in Jin's paper, but there were no follow-up studies (Jin, 2010). Lin made a comparisonamongthree different BIM software-Revit, ArchiCAD, and MicroStation-which used the Autodesk system as a tool to study BIM for traditional Chinese architecture(Lin, 2011). In that study, AutoCAD Civil 3D was the point cloud platform, with Autodesk Inventor as the tool for building elements, and Revit was used to integrate these information to building a $3 \mathrm{D}$ architectural model for the final application. However, the lifecycle information ofCultural Heritagewas not included in the BIM.

When working with the special characteristics of traditional Chinese architecture, the research on BIM in this field focused on two topics where improvements could be made:

1. When establishing databases of 3D reconstruction models of traditional Chinese architecture, BIM, currently, lacksboth structural and heritage information. For example, the Tou, Sen, Kung, their variations, structural properties, heritage values, anecdotal meanings, etc.

2. Concerning specific conservation projects, there is the intentions to setup BIM as the main tool for managing heritage building lifecycles. However, while the intention is correct, the definition of lifecycle for heritage building conservation is quite different from modern construction. Compared to modern construction, conservation work has significantly different processes, such as documentation, recording, historical research, value assessment, and final rehabilitation, restoration, or reuse.

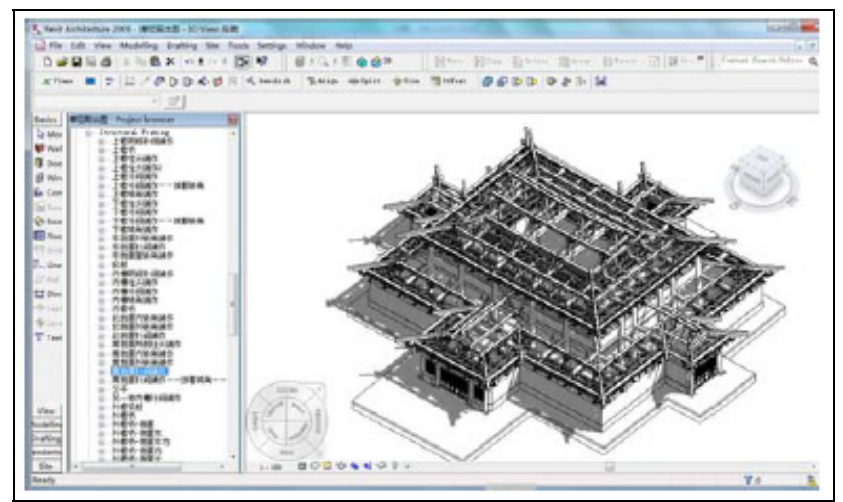

Fig 1. BIM of Chinese architectural heritages (Di,2010)

\section{METHODS AND PROCESS}

\subsection{Case Study}

This research takes the caisson ceiling of the Taipei Confucius Temple as an example. The temple was built by master carpenter Wang Yi-Shun in 1930 and has become one of Taiwan's national monuments. The caissonis located in the center of the main hall (Fig 2), supported by 4 pillars $(465.6 \mathrm{~cm} * 465.6 \mathrm{~cm} * 220.7 \mathrm{~cm}$, in $x, y, z)$ (Fig. 3). From the top of the pillars, the ceiling raises and transforms its shape from square tooctagonal, and recedes in 7 stepsto a central board. 333 wood elements in 8 types were used in its construction. During the restoration of the main hall, from 2009 to2011, the caisson ceiling was also restored,surveyed and recorded.

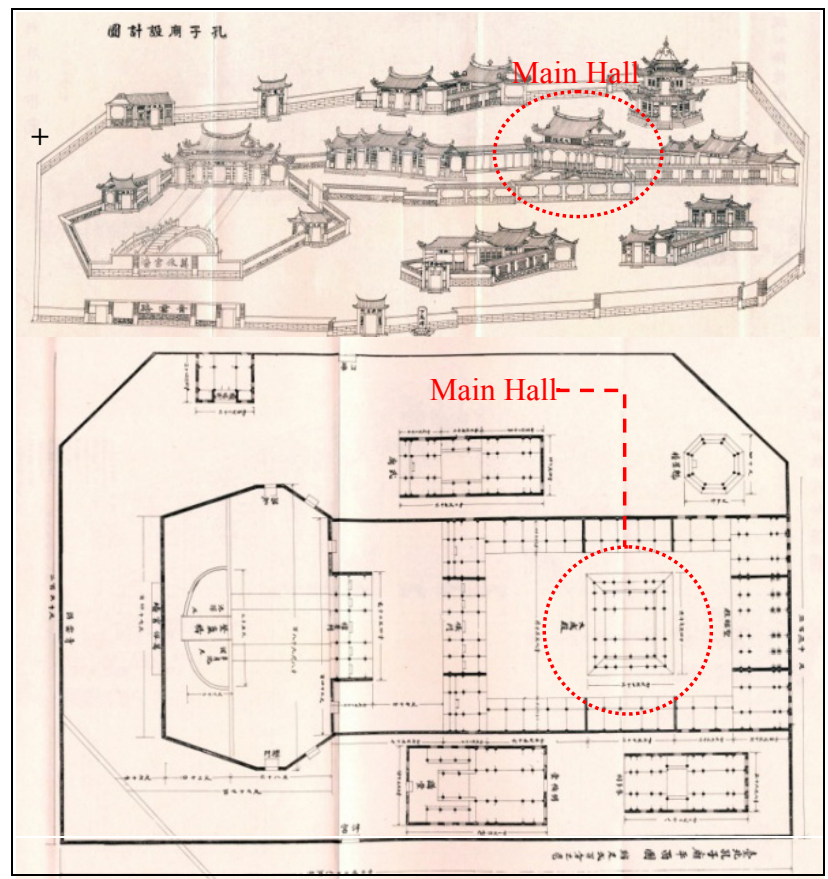

Fig 2. Main Hall of the Taipei ConfusesTemple

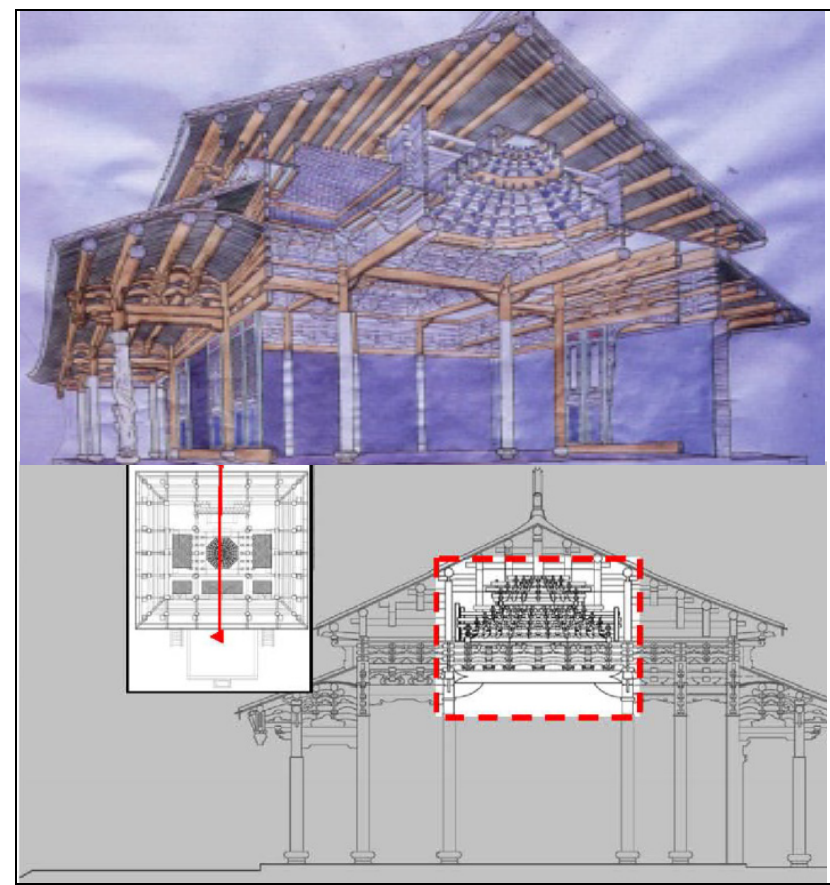


Fig 3. Section of the temple structure (above) and the caisson 3.2 Methodology ceiling (below, highlighted)

Two methods were used in this research:

a. Thesis review;

b. Metadata analysisand 3D modelling.

\subsection{Process}

a. Measuring each element and acquiring their restoration information to establish metadata for the database.

b. 3D modelling of each element, comparing Revit and SketchUp.

c. Building a complete 3D model and classification system of the caisson ceiling with SketchUp and metadata.

d. Discussing the performance of software processes and recommendation. (Fig5, 6)

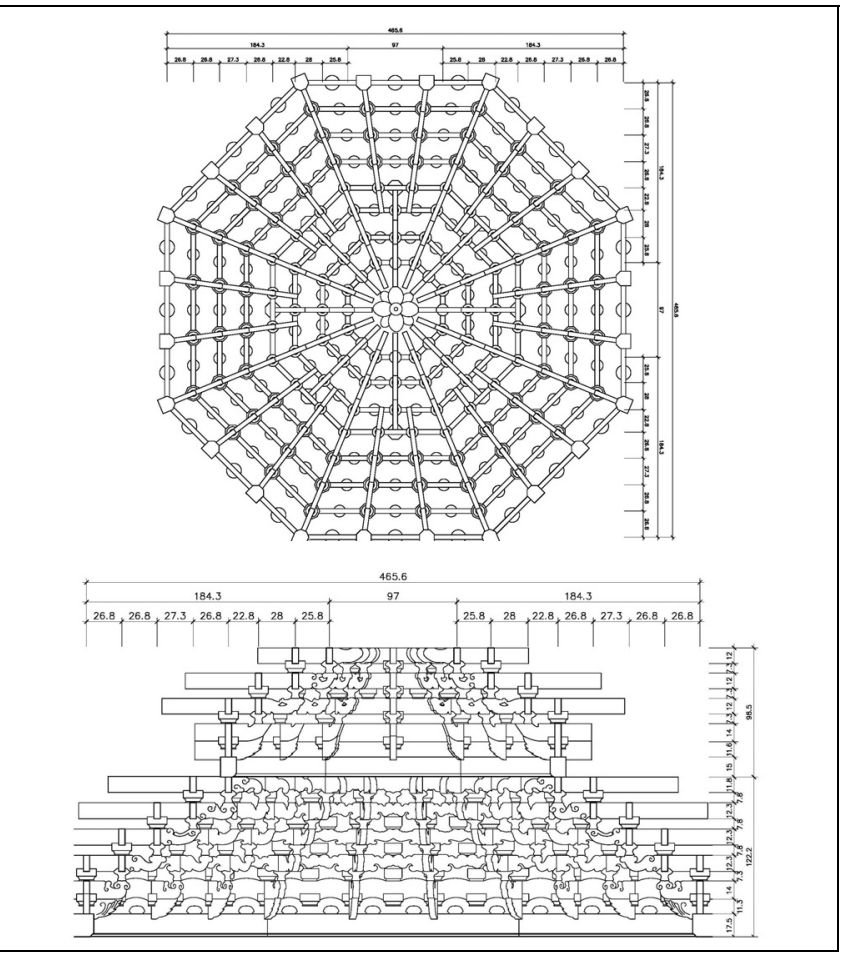

Fig 4. Plan and sectional drawings of the caisson ceiling

\begin{tabular}{|c|c|c|c|}
\hline \multicolumn{4}{|c|}{ Wooden elements of caisson ceiling } \\
\hline Type & Object Name & Form & Numbers \\
\hline 1 & Tou & 3 & 328 \\
\hline 2 & Sen & 2 & 152 \\
\hline 3 & Kung & 10 & 224 \\
\hline 4 & Linked Kung & 13 & 104 \\
\hline 5 & Connection Board & 5 & 40 \\
\hline 6 & Bevel Beam & 2 & 16 \\
\hline 7 & Board & 6 & 48 \\
\hline 8 & Center Board & 1 & 1 \\
\hline
\end{tabular}

Table 1. Caisson ceiling wooden elements metadata

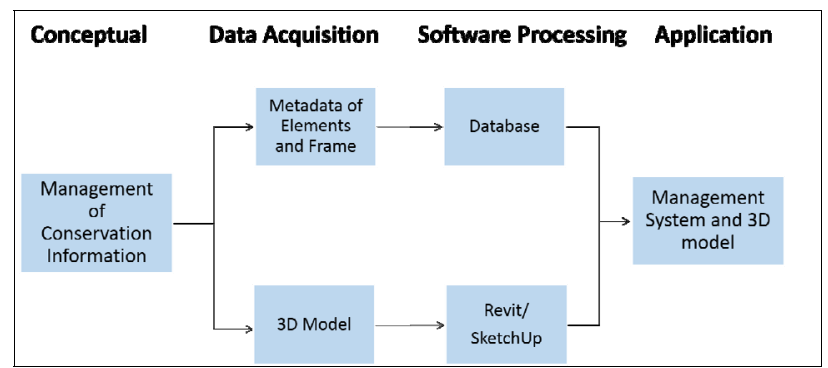

Fig 5. Digitization process

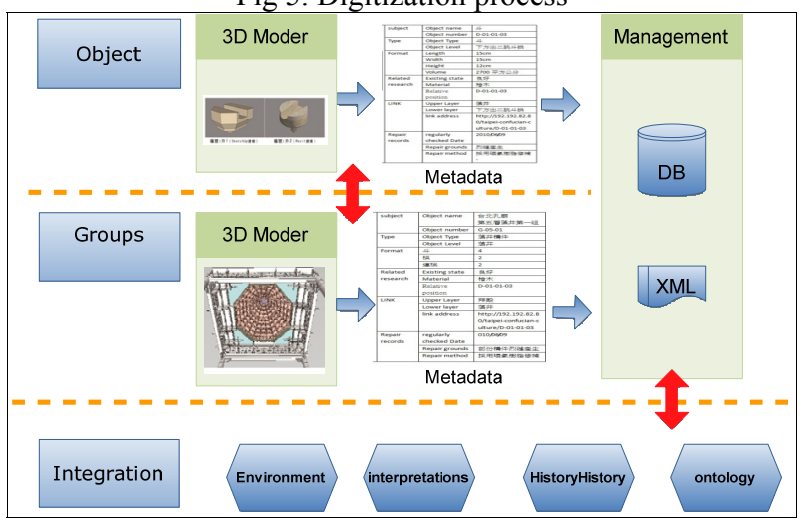

Fig 6. BIM information management architecture

\section{PROCESSING AND DISCUSSION}

\subsection{The metadata}

The IFC (Industry Foundation Classes) and IDM (Information Delivery Manual) are commonly used information exchange standards for BIM. However, for management needs, restorationinformation is very important and has to be documented. Regretfully,IFC cannot carry such data. A proper database must be established for organizing and presenting restorationinformation. Based on lifecycle considerations, information such aswhen, how, by whom and results should be the most important data alongwith basic information such as subject, type, format and related data. Other thanthat, a digital photo file which can be linkedto is needed as well. (Table 2,3)

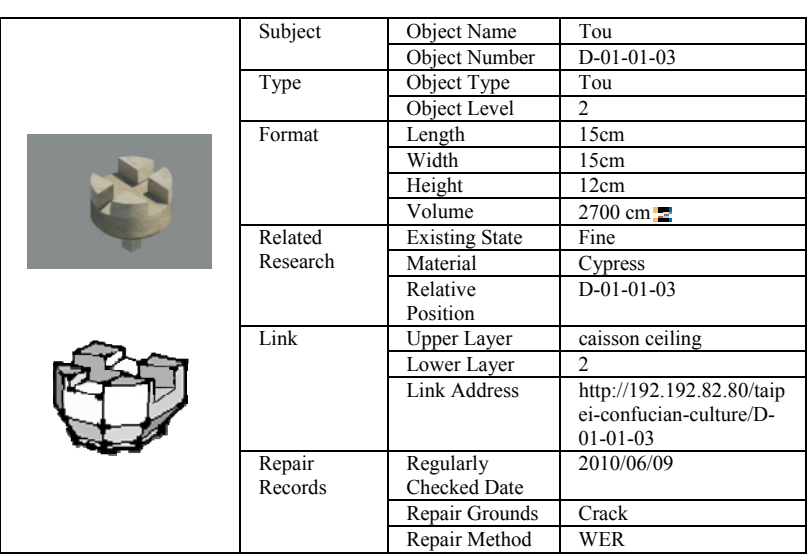

Table 2. The metadata table for the element and frame (Object)

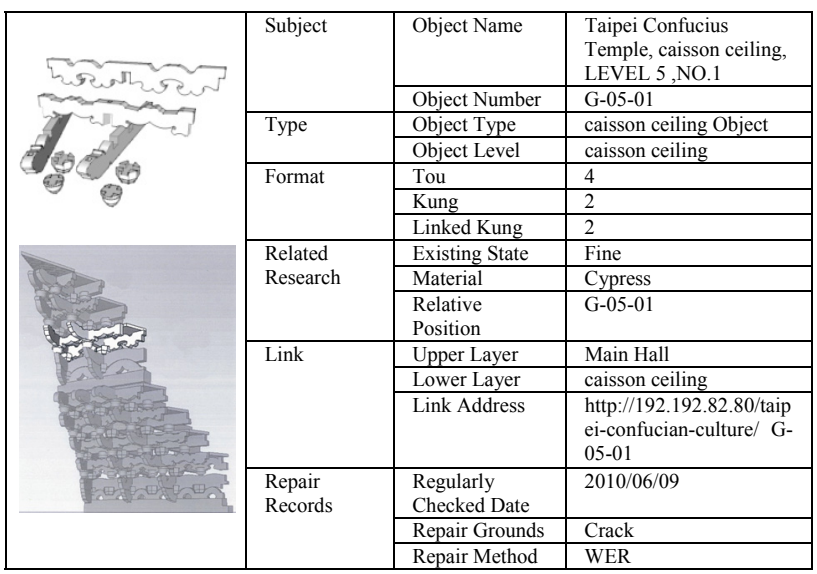

Table 3. The metadata table of elements and frame (Groups) 


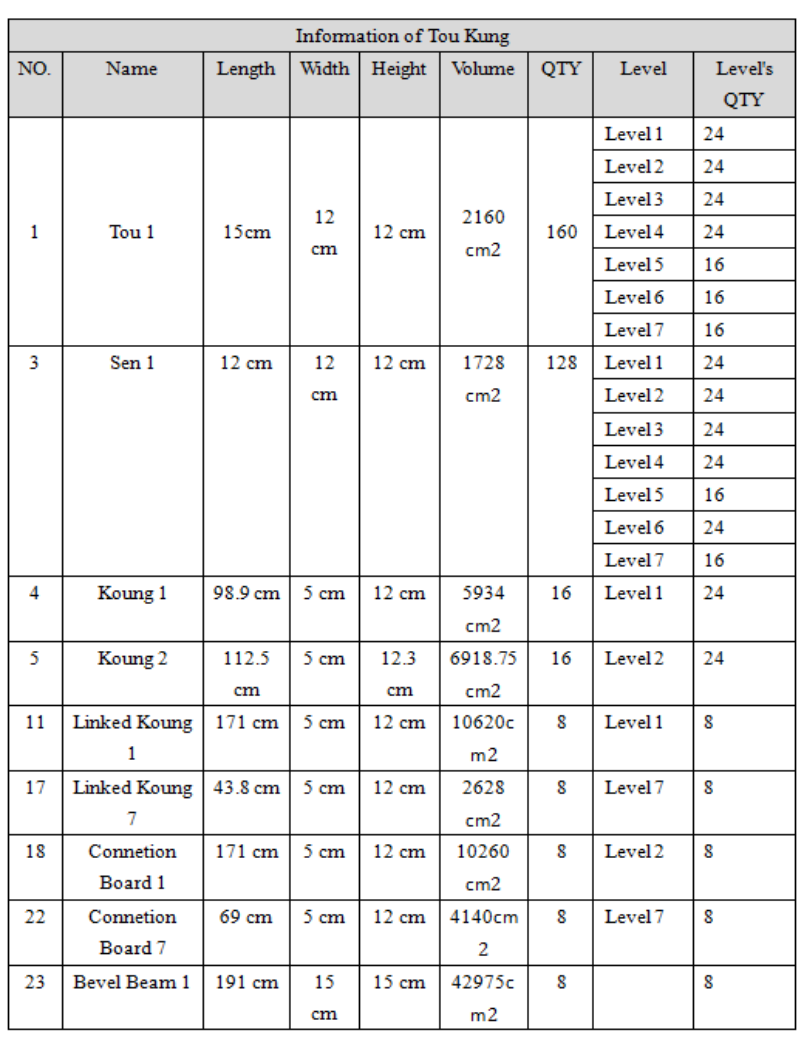

Table 4. Metadata representationof Tou Kung elements

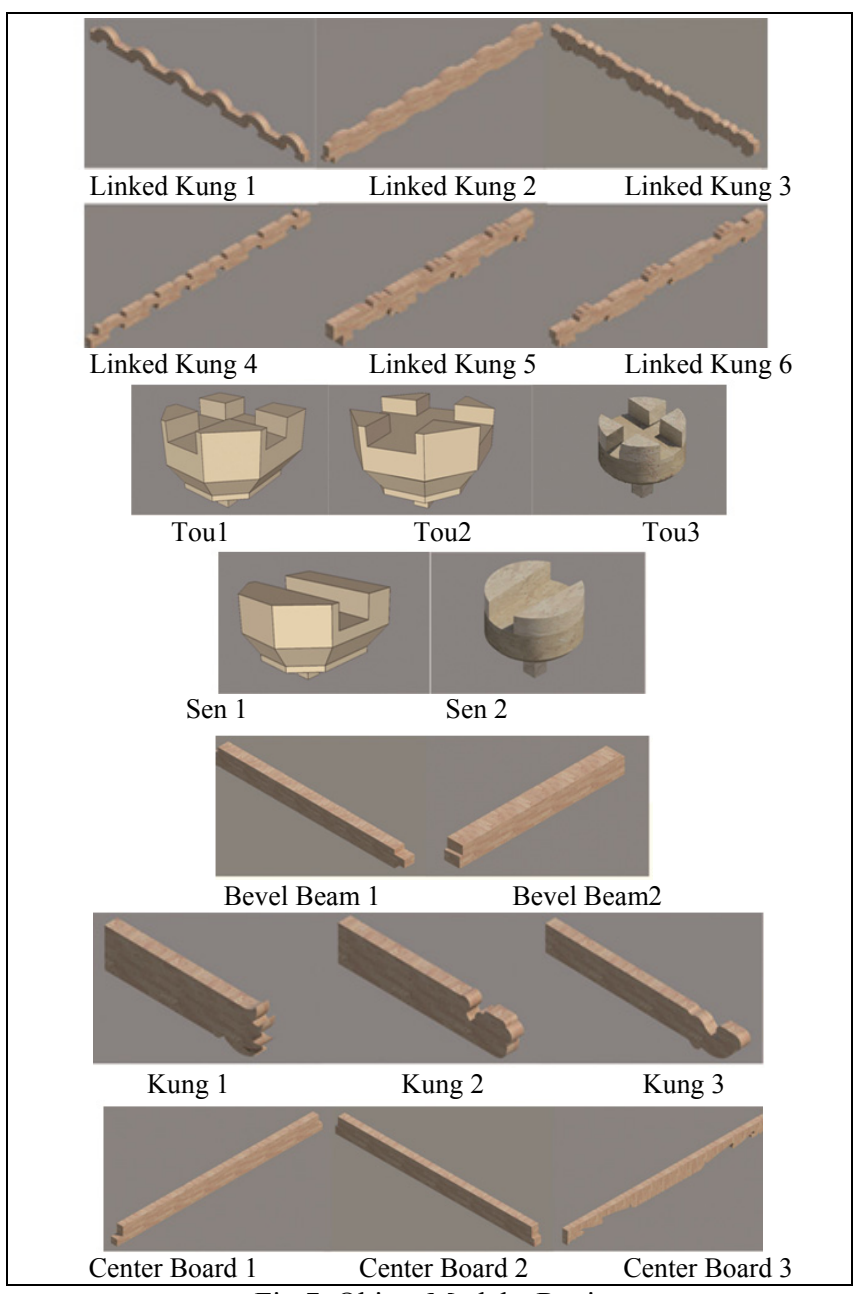

Fig 7. Object Models, Revit

\subsection{The application of Revit}

The second step is the construction of 3D models using Revit. The caisson ceiling is made up of 8 different types of structural elements, while each element of the same type looks similar, they differ incrementally in size and form. If represented only as 3D models, the inexperienced user would likely mistake them for repetitions of the same elements. However, when seen as a metadata table, this information becomes instantly more comprehensible. Because the management needs and lifecycle of cultural heritage is different from modern architecture, 3D models can only help the viewing, but not the simulation of the construction/restoration interfaces. During this research, 3D models of 16 elements in 8 types were made with Revit, then it was decided that SketchUp is the more suitable program.

\subsection{The application ofSketchUp}

SketchUp is a more efficient program to make $3 \mathrm{D}$ models for traditional Chinese Cultural Heritage for its ease of constructing and manipulating irregular forms. However, there is also an increased risk of inaccuracy that the operator much be aware of. This study used SketchUp to model all the elements and the complete frame of the caisson ceiling in the Taipei Confucius Temple using hand measured and 3D laser scanned dimensions. Integrated with the application of the metadata (Table 4), a management system for the conservation of the caisson ceiling was established.

\subsection{Metadata analysis and development}

Metadata is of the utmost importance in the conservation of cultural heritage. While 3D models in itself contains functional and dimensional data, it lacks descriptive documentation of the digitization process. The metadata could contain records of surveying and digitization processes and other importance information, such as existing conditions, alterations, planned works, modification dates, changes in personnel, areas of uncertainty etc. Traditional hand surveying and 3D laser scanning was used to produce dimensionally accurate 3D data, in the form of SketchUp models. On the other hand, interviews of local residents and management personnel, as well as historical and archival research, made up the cultural descriptive data. The present research used the Dublin Core Metadata Element Set and Getty's Categories for the Description of Works of Art for the metadata framework. Taiwan's Cultural Heritage Preservation Act and the Taiwan Digital Archives Program of the National Science Council was used to define the terms of the heritage content. Applications of the metadata are:

a. Long-term storage and organization of 3D data

b. Simplifying and streamlining future access and referencing of abundant databases.

c. Sharing of data and metadata with relevant parties.

d. Continued maintenance of cultural properties, where additional and modification information could be edited in an organized manner.
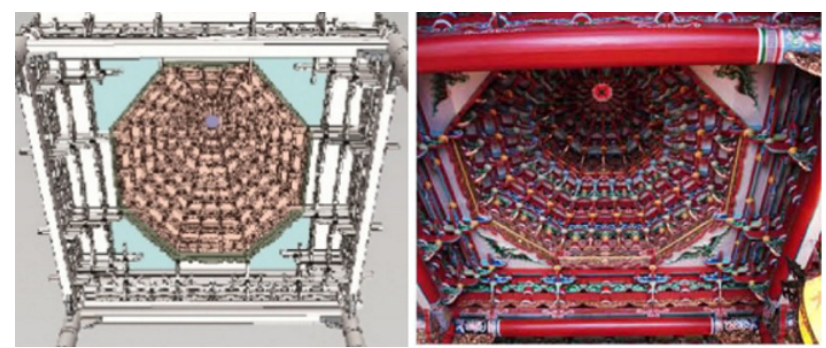

Fig 8. SketchUpmodel of caisson (left), photograph (right) 


\begin{tabular}{|c|c|c|c|}
\hline$\overline{\text { LEVEL }}$ & \multicolumn{2}{|c|}{ 3D exploded schematic } & 3D schematic \\
\hline \multirow{8}{*}{$\begin{array}{c}\text { Level } \\
1\end{array}$} & \multicolumn{2}{|c|}{$\lim _{0 \rightarrow 0}$} & \\
\hline & Object name & QTY & Object Relationship \\
\hline & Tou2 & 3 & Linked Linked \\
\hline & Tou 3 & 3 & Kung 3 Kung 4 \\
\hline & Sen2 & 3 & Kung 3 \\
\hline & Kung 3 & 3 & \\
\hline & Linked Kung 3 & 1 & $\mathbf{T}$ \\
\hline & Linked Kung 4 & 1 & \\
\hline
\end{tabular}

\begin{tabular}{|c|c|c|c|}
\hline LEVEL & \multicolumn{2}{|c|}{ 3D exploded schematic } & 3D schematic \\
\hline \multirow{8}{*}{$\begin{array}{c}\text { Level } \\
2\end{array}$} & \multicolumn{2}{|c|}{ 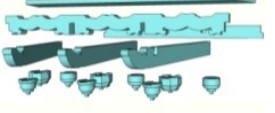 } & \\
\hline & Object name & QTY & Object Relationship \\
\hline & Tou2 & 3 & \multirow{5}{*}{$\left.\begin{array}{l}\text { Linked } \\
\text { Kung 5 }\end{array}\right) \begin{array}{c}\text { Connetion } \\
\text { Board 1 }\end{array}$} \\
\hline & Tou 3 & 3 & \\
\hline & Sen2 & 3 & \\
\hline & Kung 4 & 3 & \\
\hline & $\begin{array}{l}\text { Connection } \\
\text { Board1 }\end{array}$ & 1 & \\
\hline & Linked Kung 5 & 1 & Tou 2 $\quad$ Sen 3 \\
\hline
\end{tabular}

\begin{tabular}{|c|c|c|c|}
\hline LEVEL & \multicolumn{2}{|c|}{ 3D exploded schematic } & 3D schematic \\
\hline \multirow{9}{*}{$\begin{array}{c}\text { Level } \\
\mathbf{3}\end{array}$} & \multicolumn{2}{|c|}{ 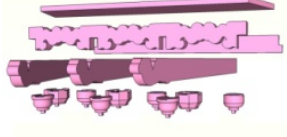 } & \\
\hline & Object name & $\overline{\text { QTY }}$ & Object Relationship \\
\hline & Tou2 & 3 & Connetion \\
\hline & Tou 3 & 3 & Kung 6 \\
\hline & Sen2 & 3 & \\
\hline & Kung 5 & 3 & Kung 5 ) \\
\hline & Linked Kung 6 & 1 & $\mathbf{T}$ \\
\hline & Connection & 1 & \\
\hline & board 2 & & Tou 2 ) \\
\hline
\end{tabular}
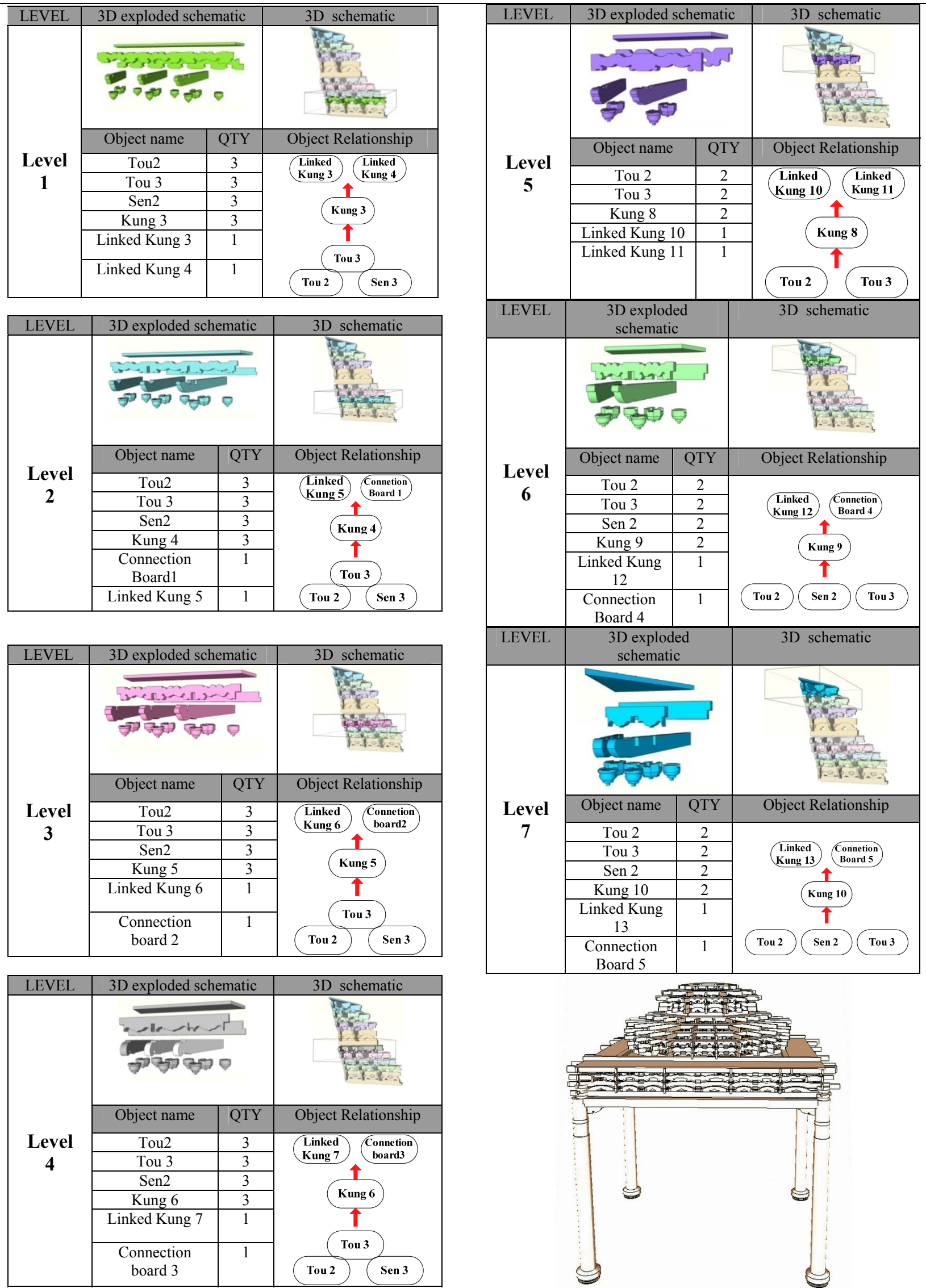

Table 5. 7Levels of caissonceiling construction,SketchUp and metadata representation

\section{DISCUSSION}

1. Typically, the numeroustypes of traditional Chinese architecture embodies more than thousands of elements.

Different habits of workers can lead to handmade elements of varying sizes and shapes. This special characteristic is a 
part of what makes traditional Chinese architecture so impressive, but also increases the difficulty of accurate recording and authentic restoration. 3D modelling of architectural elements can helpreconstructaccurate representations; however, this model cannotcontain all the required information for conservation.

2. The lifecycle of cultural heritage, especially restoration information, have mainly been recorded in papers, photos and other digital documents. Among these, the locations, shapes, sizes, textures, and the restoration processes of elements are critical data that can be effectively stored and presented using metadata platforms.

\section{CONCLUSION}

This article has set up a management system for the restoration of 333 caisson ceiling elements in the TaipeiConfuciusTemple. During the process, two conclusions are made:

1. The management of conservation information for cultural heritage needs a well-designed database together with an easy-to- understand visual model. In this case, SketchUp is the recommended tool for 3D modelling.

2. Based on a standard element database, BIM and other 3D modelling tools help to imitate the layout of objects. For the conservation oftraditional Chinese architecture,unless we establish 3D models for each element, one by one, the record could be inaccurate from the real situation and the needs of conservation.

\section{FUTURE WORKS}

The application of BIMto manage cultural heritage requires different methodologies frommanaging modern architecture. Conservation information of each element is unique and should be concisely recorded.Management systems for cultural heritage could be established according to the following requirements:

e. Research knowledge structure on managing conservation information of individual element.

f. Identify the relation between different objects and to meet the management need.

g. Develop an individual database for managing conservation information and set up a HBIM for simulation or integrating with other digital systems.

\section{REFERENCES}

Di, Y., Wu, C., 2010. Research on the building information model for the building lifecycle information management of architecture heritages in China. International conference on Services Science, Management and Engineering, pp. 283-286, (Ch).

Dore, C., 2012. Integration of historic building information modelling (HBIM) and 3d GIS for recording and managing cultural heritage sites, Dublin Institute of Technology, pp. 369375 .

Fai, S., 2011. Building information modelling and heritage documentation. XXIII CIPA Symposium.

Huang, M., Jin, J., 2010/09/02-03. Information exchange study of traditional building database establishment based on open BIM technology. Journal of Information Technology in Civil Engineering and Architecture, (Ch).

Lin C. C., 2011. The case study in preserving heritage using building information modelling. 2011 Conference on the Digitization and application of Historic Buildings, China University of Technology, Taipei, Taiwan, (Ch).

Murphy M., 2011. Historic building information modelling adding intelligence to laser and image based surveys. ISPRS Trento 2011 Workshop.

Tan, J., 2006. A primary research on the $3 \mathrm{~d}$ parametric design for the wooden elements of traditional qing dynasty architecture based on the GDL technique. Chongqing University, (Ch)

Berlo L. V., 2011. Integration of BIM and GIS: the development of the CityGMLGeoBIM extension. Advances in $3 D$ Geo-Information Sciences, Springer. 